\title{
Prostatic ductal adenocarcinoma presenting with hemospermia
}

\author{
Tafadzwa P Makarawo, Jeffrey L O’Connor
}

\begin{abstract}
Introduction: Ductal (endometrioid) adenocarcinoma is a rare form of prostate cancer that most often presents with local obstructive or irritative symptoms such as acute urinary obstruction and hematuria, often in the presence of a normal prostate specific antigen (PSA) value. Hemospermia is a symptom rarely associated with prostate malignancy. Therefore, this was not investigated extensively in the past, requiring only patient reassurance and empiric antibiotic treatment. Case Report: A 56-year-old male presented with complaints of hemospermia. His physical examination was unremarkable and serum PSA was within normal limits. He was, therefore, reassured and given a course of antibiotics. However, due to persistent hemospermia symptoms, he underwent a flexible cystoscopy which identified a polypoid lesion within the verumontanum of the prostatic urethra, which upon resection was found to be prostatic ductal adenocarcinoma. Following an initial period of surveillance, the patient underwent a radical prostatectomy from which he made an uneventful recovery and remained disease-free up to the last follow-up six months before. Conclusion: Hemospermia is a symptom largely considered to be benign but in some
\end{abstract}

Tafadzwa P Makarawo ${ }^{1}$, Jeffrey L O'Connor ${ }^{1}$

Affiliations: ${ }^{1}$ Providence Hospital and Medical Centers, 16001 West Nine Mile, Rd, Southfield, MI.

Corresponding Author: Dr. Tafadzwa P. Makarawo, MD, Department of Surgery, Providence Hospital and Medical Centres, 16001 W Nine Mile Road, Southfield, Michigan, United States, Tel: +1-248-849-3000, Fax: +1-248-8495324; Email: taffyowm@yahoo.com

Received: 05 June 2012

Accepted: 20 August 2012

Published: 01 December 2013 patients it should motivate thorough clinical evaluation for ductal prostatic adenocarcinoma.

Keywords: Ductal adenocarcinoma, Endometrioid, Hemospermia, Prostate

$$
* * * * * * * * *
$$

Makarawo TP, O'Connor JL. Prostatic ductal adenocarcinoma presenting with hemospermia. International Journal of Case Reports and Images 2013;4(11):682-685.

$* * * * * * * * *$

doi:10.5348/ijcri-2013-12-410-CR-4

\section{INTRODUCTION}

Prostatic ductal (endometrioid) adenocarcinoma is a rare variant of prostate adenocarcinoma presenting in $0.13-6 \%$ of all prostate cancers [1]. As with acinar prostate adenocarcinoma, ductal adenocarcinoma affects elderly men over the age of sixty-five. However, in ductal adenocarcinoma, there exist some important differences in its presentation. Whereas acinar prostate adenocarcinoma cases are most often diagnosed through screening by asymptomatic increases in prostate specific antigen (PSA), ductal adenocarcinoma is known to present with local obstructive or irritative symptoms such as acute urinary obstruction and hematuria, often in the presence of a normal PSA value [1].

Hemospermia is an uncommonly reported symptom that historically did not warrant further investigation at presentation [2]. In recent years, there has been a growing body of evidence in support of its association with urological malignancy [3]. We add to this body of evidence a case of prostatic ductal adenocarcinoma presenting with hemospermia, with only one other case describing this association in literature [4]. 


\section{CASE REPORT}

A 56-year-old male was presented with complaints of hemospermia. His PSA was below 0.1, urinalysis was negative, and digital rectal examination was normal. He was, therefore, reassured and given a course of antibiotics.

One month later, his symptoms had not resolved despite a course of antibiotics. Flexible cystoscopy was, therefore, performed and revealed no evidence of bladder malignancy but noted an inflammatory-looking polyp extending off the right portion of the verumontanum. A transurethral resection of the abnormality revealed histological features consistent with ductal adenocarcinoma (Figures 1 and 2). Specifically, tall, pseudostratified, columnar cells with abundant cytoplasm arranged in a predominantly papillary pattern were seen on H\&E stain (Figure 1), with PSA immunohistochemistry staining verifying the prostatic origin of the malignancy (Figure 2) and distinguishing it from colorectal cancer invading the prostate.

Following an initial period of active surveillance elected by the patient, he eventually underwent a radical prostatectomy. Final pathological evaluation of the prostate specimen indicated a focus of Gleason score 7 $(4+3)$ ductal adenocarcinoma with two foci of acinar adenocarcinoma of Gleason score $8(4+4)$. Surgical margins were negative.

The patient had an uneventful postoperative recovery and remained disease-free on follow-up visits.

\section{DISCUSSION}

Ductal adenocarcinoma has unique morphological and clinical features. Histologically, it is characterized by the presence of tall, pseudostratified, columnar cells with abundant cytoplasm arranged in a papillary pattern [1]. Typically, these lesions grow as exophytic lesions into the urethra, most commonly around the verumontanum [1]. The exophytic growth into the urethra accounts for the clinical presentation of obstruction and hematuria. Mimickers of ductal adenocarcinoma include prostatic urethral polyps, hyperplastic benign prostate glands, High-grade prostatic intraepithelial neoplasia (PIN), colorectal adenocarcinoma, and papillary urothelial carcinoma. The diagnosis of ductal adenocarcinomas is made more challenging by the fact that they may not always present with an elevated PSA and transrectal ultrasound biopsy can miss these largely central tumors, diagnosis often being made incidentally following radical prostatectomy $[1,5]$.

Hemospermia is defined as the presence of fresh or altered blood in the ejaculate [2]. The exact incidence of hemospermia remains unknown as most ejaculates go unnoticed during intercourse. The etiology of hemospermia has been described as largely idiopathic, reported in as many as $70 \%$ of all presenting cases [2], with a variety of other less common causes described previously (Table 1).

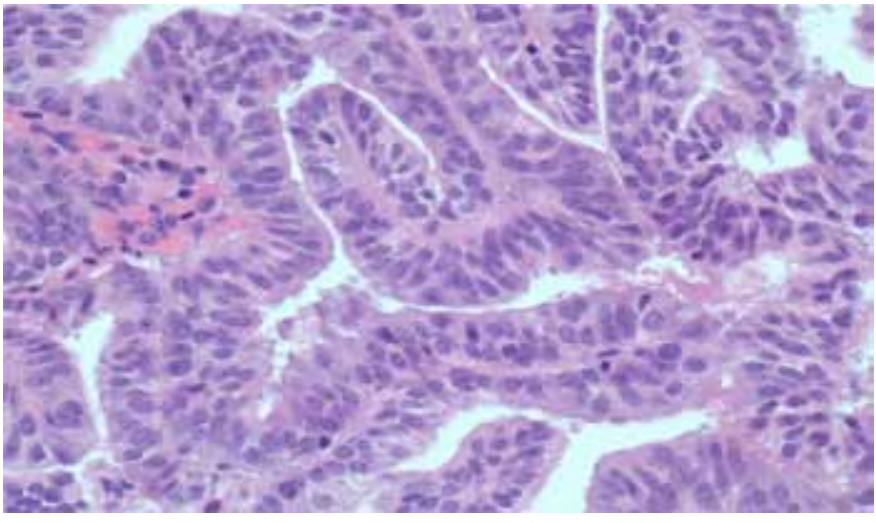

Figure 1: Resected prostatic urethral polyp showing tall, pseudostratified, columnar cells with abundant cytoplasm arranged in a predominantly papillary pattern, features consistent with ductal adenocarcinoma (H\&E stain, x400).

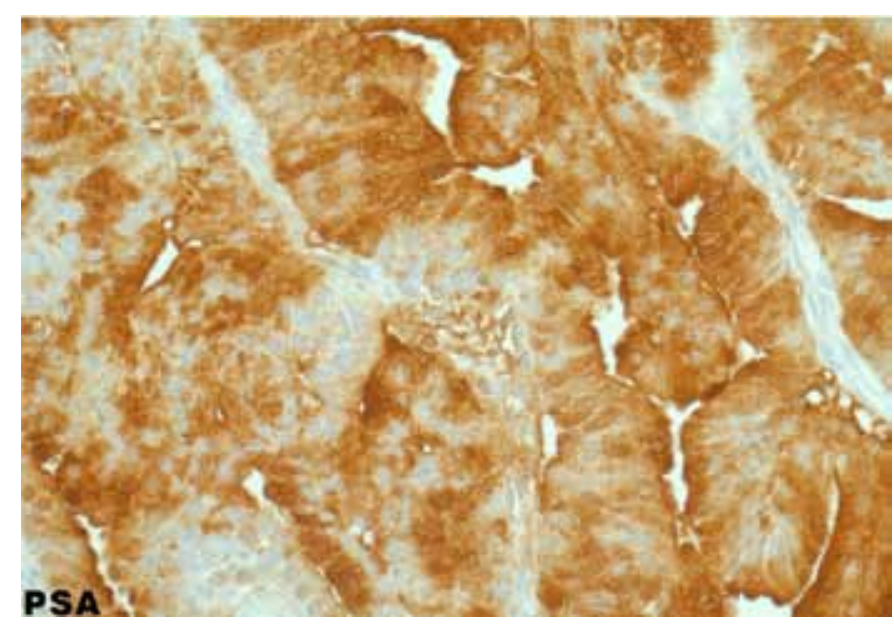

Figure 2: Immunohistochemical stain showing PSA expression, typical for ductal adenocarcinoma of the prostate (PSA, x400).

Table 1: Etiology of Hemospermia

\begin{tabular}{|c|c|}
\hline Congenital & Seminal Vesical/ejaculatory duct cysts \\
\hline Inflammatory & $\begin{array}{l}\text { Urethritis, prostatitis, epididymitis, } \\
\text { Cytomegalovirus (CMV), HIV }\end{array}$ \\
\hline Obstruction & $\begin{array}{l}\text { Prostatic and Seminal Vesical and ejaculatory } \\
\text { duct calculi, benign }\end{array}$ \\
\hline Tumors & $\begin{array}{l}\text { Prostate, Bladder, Seminal vesical, Urethra, } \\
\text { Testis, Epididymis }\end{array}$ \\
\hline Vascular & $\begin{array}{l}\text { Prostatic varices, prostatic telangiectasia, } \\
\text { hemangioma }\end{array}$ \\
\hline Trauma & $\begin{array}{l}\text { Perineum, testicle, Self-instrumentation, } \\
\text { Transrectal ultrasound biopsy }\end{array}$ \\
\hline Systemic & $\begin{array}{l}\text { Hypertension, hemophilia, Purpura, Scurvy, } \\
\text { Bleeding diatheses }\end{array}$ \\
\hline
\end{tabular}

Prostate acinar adenocarcinoma has a documented association with hemospermia. Recent evidence provided by our colleagues found that of the screened prostate cancer patients that presented with hemospermia (0.5\%), $13.7 \%$ of this cohort of patients was diagnosed with 
prostate cancer [3]. Due to the largely benign nature of most causes of hemospermia (Table 1) with the majority resolving spontaneously, it was previously advocated that hemospermia required no further investigation, requiring patient reassurance and empiric antibiotic treatment [6]. However, as this case demonstrates, hemospermia identified in the elderly population should always raise the suspicion for malignancy and as such reassurance should only be provided once extensive evaluation has excluded such etiologies. Transrectal ultrasound biopsy followed by magnetic resonance imaging (MRI) or computed tomography (CT) to further assist in visualizing the anatomy of pelvic organs are essential components in the evaluation of these patients [7]. Flexible cystoscopy has been suggested to be the final step in the evaluation of hemospermia, being useful in direct visualization of urethritis, urethral polyps or calculi, vascular anomalies, foreign bodies and bladder neck varicosities.

We accept that acinar prostate adenocarcinoma has a reported, though rare, association with hemospermia, but to our knowledge, this is only the second reported case in English literature, specifically, describing this symptom in association with the ductal variant of prostatic adenocarcinoma.

Our case also reiterates some of the difficulties associated with diagnosing ductal adenocarcinoma of the prostate. Physical examination and serum PSA levels were both non-specific in identifying the cause of the patient's symptoms and in the end, the presence of persistent obstructive urinary symptoms and hemospermia influenced the decision to perform flexible cystoscopy earlier in the evaluation, a step that eventually yielded the diagnostic result.

\section{CONCLUSION}

Hemospermia is a symptom largely considered to be benign but in elderly patients with co-existing urological symptoms, the increased odds of prostate cancer detection should motivate thorough clinical evaluation for ductal prostatic adenocarcinoma.

\section{Author Contributions}

Tafadzwa Makarawo - Substantial contributions to conception and design, Acquisition of data Drafting the article, Revising it critically for important intellectual content, Final approval of the version to be published Jeffrey O'Connor - Substantial contributions to conception and design, Drafting the article, Final approval of the version to be published

\section{Guarantor}

The corresponding author is the guarantor of submission.

\section{Conflict of Interest}

Authors declare no conflict of interest.

\section{Copyright}

(C) Tafadzwa Makarawo et al. 2013; This article is distributed under the terms of Creative Commons attribution 3.0 License which permits unrestricted use, distribution and reproduction in any means provided the original authors and original publisher are properly credited. (Please see www.ijcasereportsandimages.com/ copyright-policy.php for more information.)

\section{REFERENCES}

1. Epstein JI. Prostatic Ductal Adenocarcinoma: A mini review. Medical Principles and Practice 2010;19:825 .

2. Szlauer R, Jungwirth A. Hematospermia: Diagnosis and Treatment. Andrologia 2008;40:120-4.

3. Han M, Brannigan RE, Antenor JA, Roehl KA, Catalona WJ. Association of hemospermia with prostate cancer. Journal of Urology 2004;172:21892.

4. Rubinowicz DM, Soloway MS, Lief M, Civantos F. Hemospermia and expressed tumor in the urethra: An unusual presentation of ductal carcinoma of the prostate. Journal of Urology 2000;163:915.

5. Tu SM, Lopez A, Leibovici D, et al. Ductal Adenocarcinoma of the Prostate. Clinical Features and Implications After Local Therapy. Cancer 2009;115:2872-80.

6. Kumar P, Kapoor S, Nargund V. Hematospermia- a systematic review. Annals of the Royal College of Surgeons of England 2006;88:339-42.

7. Fuse H, Nishio $R$, Murakami, Okumura A. Transurethral incision for hematospermia caused by ejaculatory duct obstruction. Archives of Andrology 2003;49:433-8. 
Access PDF of article on other devices

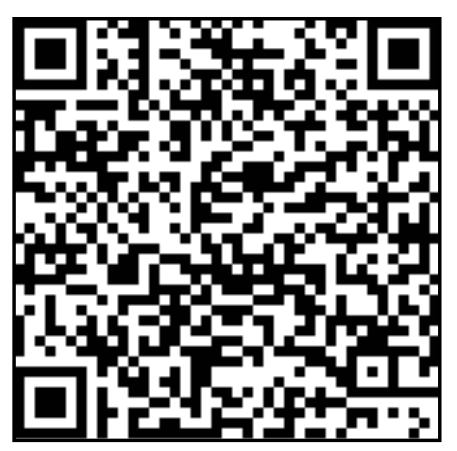

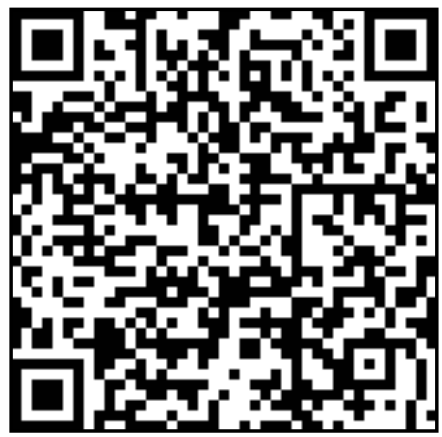

